\title{
TA Treatment of Depression - A Hermeneutic Single-Case Efficacy Design Study - 'Tom'
}

\author{
(C) 2012 Mark Widdowson
}

\begin{abstract}
Hermeneutic Single-Case Efficacy Design (HSCED) is a systematic case study research method involving the cross-examination of mixed method data to generate both plausible arguments that the client changed due to therapy and alternative explanations. The present study uses HSCED to investigate the outcome of shortterm TA psychotherapy with a man with moderate depression and comorbid social anxiety The objective of the research was to investigate the effectiveness of short-term TA therapy for the treatment of depression and to explore and identify key aspects of the TA therapy process and associated factors promoting change amongst effective cases. To enhance rigour and address potential for researcher allegiance, independent psychotherapy researchers have adjudicated the case and offer a verdict on outcome. The majority verdict of two judges in this case was that this was a positive outcome case and that the client had changed substantially and that these changes were substantially due to the effects of therapy. The third judge's conclusion was that this was a mixed outcome case, and that the client had changed considerably and that this had been considerably due to therapy.
\end{abstract}

This is the $3^{\text {rd }}$ case reported on and additional rigour was introduced into the HSCED approach in the same way as reported in the accompanying paper about the $2^{\text {nd }}$ case. (IJTAR 3:2, 3-14)

\section{Key words}

Depression; Hermeneutic Single-Case Efficacy Design; Case Study Research; Transactional Analysis Psychotherapy.

Editor's Notes: For the $1^{\text {st }}$ paper in this series, which appeared in IJTAR 3:1, the author provided detailed appendices: the case record, affirmative and sceptic cases, judges' opinions, and various templates including adherence checklists.

\section{Introduction}

This article presents the case of 'Tom', a 38 year old white British male builder who engaged in short-term TA psychotherapy for the treatment of depression and social anxiety. This article is the third in a series of systematic case studies (Iwakabe \& Gazzola, 2009; McLeod, 2010) conducted by the author as part of his doctoral research investigating the process and outcome of (short-term) TA psychotherapy for the treatment of depression. In line with the previous cases in this series (Widdowson, 2012a, 2012b), the aim of this present case was to use case study methodology to analyse the effectiveness of TA therapy for the treatment of depression and to conduct a detailed analysis regarding the process of therapy.

This present case contributes to the literature on outcomes of TA psychotherapy for treatment of depression in the same way as described for the $2^{\text {nd }}$ case (Widdowson 2012b) so that rationale and review of prior research will not be repeated here. In summary, this present case uses Hermeneutic Single-Case Efficacy Design (HSCED) (Elliott, 2001, 2002; Stephen \& Elliott, 2011), enhanced as described for the $2^{\text {nd }}$ case, to 'evaluate the efficacy of psychotherapy on a case by case basis by asking:

- "Did the client change substantially over the course of therapy?

- Is this change substantially due to the effect of the therapy?

- What factors (including mediator and moderator variables) may be responsible for the change?" (Stephen \& Elliott, 2011; 231)

Increasingly, psychotherapy researchers are questioning the dominance of Randomised Controlled Trials (RCT's) within psychotherapy research and are calling for an integrated research approach which in 
addition to RCT evidence also incorporates a range of other research methods including practice-based, qualitative and systematic case study research (Barkham et al 2010; Dattilio et al, 2010; McLeod \& Elliott, 2011).

Whilst large $n$, quantitative studies (such as RCT's) have been incredibly useful in establishing the efficacy of psychotherapy, both within tightly-controlled conditions as well as in routine practice (such as Stiles, et al, 2008), these studies have not been able to provide detailed information regarding the specific factors which have influenced the change process in individual clients (McLeod \& Elliott, 2011). Although RCT's are generally considered to be high in internal validity, Datillio et al (2010) consider RCT's to have problems with internal validity due to not accounting for 'softer', more intangible variables such as therapist responsiveness, therapeutic alliance, the impact of client hope and their perceptions of the therapist's credibility.

McLeod \& Elliott (2011) describe some particular strengths of case study research as including the ability to account and allow "for the identification and analysis of complex patterns of interplay between different factors or processes" (p. 3) including contextual factors within each case, detailed exploration of how change takes place over time, and providing practice-relevant and accessible information for practitioners.

They go on to state that "the quality of evidence generated by . . . intensive single-case outcome studies, is in many respects more credible than the evidence produced by RCTs and other large-scale studies. Because they use many different sources of information, readers and reviewers can be confident that systematic outcome-oriented case studies reflect the most accurate appraisal that is possible of the extent to which a client has been helped by therapy. By contrast, large-scale studies represent aggregations of outcome estimates based on much more limited evidence for each case. The value of case study evidence in establishing the effectiveness of therapeutic intervention has been recognised by several leading authors on evidence-based policymaking (e.g. APA Presidential Taskforce, 2006; Chambless \& Hollon, 1998; Edwards, Dattilio, \& Bromley, 2004; Medical Research Council, 2008)." (p. 7). They also note that the majority of published systematic case studies are of therapy conducted in university research clinics and that there is a paucity of published cases of therapy as it tends to be conducted in everyday, routine clinical practice with the type of clients who tend to present for therapy in routine practice.

This present case series is different in that all of the therapists participating in this case series were working in the type of settings that many therapists practice in (this and the previous two cases were of therapy conducted in private practice) and the clients were all clients who self-referred and presented for psychotherapy. In order to learn more about what TA psychotherapists actually do in practice, the therapy in this case series was subject to limited amounts of intrusion in the therapy process and therapists were invited to conduct the therapy as closely to what they would normally do, with the obvious exceptions of the recording procedures required for the research. Similarly, very limited inclusion and exclusion criteria were applied to ensure that the clients in this case series most closely resembled the type of clients that most therapists might encounter on a daily basis. The intention here was to facilitate the process of generalisation from this case series and the transfer of the research findings by therapists into their practice.

This present case analyses the process and outcome of sixteen sessions of TA therapy with 'Tom'. A central feature of Tom's depression and social anxiety was his self-critical internal dialogue and a significant amount of the therapy was focused on addressing this selfcriticism, which was conceptualised as a negative ego state dialogue. Self-criticism has been recognised as a significant component of depression (Bagby, et al 1992) and social anxiety (Cox, et al 2000; Cox, et al 2004) and it has been speculated that it is possible that these disorders share a common pathway of introjective psychopathology (Blatt, 1991) which is characterised by low self-esteem, feelings of inferiority, negative beliefs about one's value and worth and negative comparison to others. It would appear that these introjective aspects of the process of depression and social anxiety are also a feature of a number of other psychological disorders, making self-criticism an important transdiagnostic clinical concept and one which may prove fruitful for change when it is the focus of sustained and intensive therapeutic efforts.

Self-criticism is presumed to originate in negative relational experiences which become introjected into the individual's psyche where they are replayed internally (Blatt, 1991) and it has been suggested that therapy which intensively targets self-criticism may have a substantial impact on depression, social anxiety and other introjective disorders (Cox, et al 2002; Cox, et al 2004). Sachs-Ericsson et al (2006) also noted a relationship between parental verbal abuse and selfcriticism and internalizing symptoms - a factor which appears to have been relevant in Tom's case. Within a TA framework, self-criticism tends to be viewed as a negative internal dialogue between Parent and Child ego states (Berne, 1972; Goulding \& Goulding, 1979; Woollams \& Brown, 1979; Stewart \& Joines, 1987; Clarkson, 1992; Widdowson, 2010) 


\section{Method}

Participants

Client

Tom was a 38 year old white British builder, who presented for private, weekly TA psychotherapy. Contrary to what one might expect from his tall, muscular build, he described feeling anxious and intimidated socially and feeling very down. He described problems with communicating with people, and often crippling levels of social inhibition. He felt he was stupid and useless, and had very poor self-esteem. He described what sounded like a relentless self-critical internal dialogue which was making him feel depressed. He described low mood, a loss of interest in things and feeling pessimistic and despondent about the future. Tom had a very difficult upbringing and was treated harshly, particularly by his mother and had been bullied at school for having some speech difficulties.

He was in a long term, long distance relationship, which was generally positive, although he often also felt inhibited around his partner's three children. He felt that his low mood, lack of interest and social inhibition was harming his relationship with his partner, and also preventing him from building his relationship with her children.

Tom had received six sessions of counselling in a primary care setting several years previously due to his difficulties with relating to others. He found this experience supportive but limited. Just prior to engaging in the therapy presented here, he had become interested in transactional analysis and had read several books about TA. He found his reading on TA theory to be helpful and as a result actively sought out a TA therapist.

At the intake interview, the therapist determined that Tom did not meet any excluding criteria for participation in the study (psychosis, domestic violence, active drug/ alcohol abuse) and conducted a brief clinical diagnostic interview to confirm diagnosis of major depressive disorder based on DSM-IV diagnostic criteria (APA, 1994). Tom also met diagnostic criteria for comorbid social anxiety disorder. Tom's clinical score at point of entry to therapy using CORE-OM was 18, indicating mild levels of distress and functional impairment and his BDI-II score was 24 , indicating moderate depression. Tom was given an information pack about the research project and invited to participate.

He completed an informed consent form at the beginning and end of therapy and during the follow-up procedure. He was seen in a naturalistic therapy protocol for sixteen weekly sessions. Audio recordings were made of the sessions and several sessions have been randomly checked by the researcher for adherence to TA therapy and for quality checking and were rated as excellent both in quality and adherence by the therapist, the supervisor and the researcher. Using a members checking procedure, Tom was given the 'rich case record' to review and to confirm his consent for the document to be used and he agreed that it was an accurate representation of the therapy.

\section{Therapist and Treatment}

The therapist in this case was 'Julie' who was a white, British therapist with over ten year's post-qualifying experience. Julie had at least one hour per month of supervision on this case with a Teaching and Supervising Transactional Analyst (Psychotherapy). Due to ethical concerns relating to preserving the client's confidentiality and anonymity, further details of the therapist have been withheld from this article.

The therapist provided short-term TA therapy which worked to the therapeutic tasks shown in the Adherence Checklists (Widdowson, 2012: App 7\&8). As the research was a naturalistic study, the therapist conducted the therapy in line with their usual practice and procedures and created an individualised approach to match the client's needs.

The initial phase of the therapy involved a collaborative and active diagnostic and intervention approach. Session one focused on problem formulation and negotiating therapy contract goals, then this phase (sessions 2-4) consisted of Identifying life experiences which had shaped Tom's script and formed the basis of his self-critical negative ego state dialogue and his racket system. Tom's emotional reactions to these life events were identified and the therapist adopted an empathic approach of affirmation, validation and normalisation of these reactions to encourage the internalisation of a more nurturing internal dialogue. The initial phase concluded with two sessions utilising two-chair method for Identifying and challenging his negative ego state dialogue and script beliefs.

The middle phase of the therapy (sessions 5-9) focused on identifying and re-evaluating early life experiences which formed his script and self-critical ego state dialogue and on identifying current interpersonal patterns that reinforce these. This phase also included challenging the self-critical dialogue and negative introject and using self-reparenting strategies to install a positive nurturing/ soothing ego state dialogue.

The final phase of the therapy focused on communication, interpersonal learning, changing interpersonal patterns and supporting change in internal ego state dialogue. The therapy concluded with a review of the process and identifying resources for future change. A full account of the therapy is contained in the rich case record which is available from the author on request. 
Analysis Team

The analysis team who generated the affirmative and sceptic arguments was comprised of 7 students in training for the Certified Transactional Analyst (Psychotherapy) qualification, who attended a full-day case study research analysis workshop. All postfoundation year trainees at the training institute involved were sent an e-mail invitation to attend and participants in the analysis self-selected. The workshop was intended to provide experiential learning of case study research analysis and was co-facilitated by the author and Katie Banks, Certified Transactional Analyst (Psychotherapy). (Ms Banks had participated in the analysis of the case of 'Peter'). Participants had been sent copies of the rich case records, plus an article describing the HSCED method one week prior to the workshop. The workshop commenced with a one-hour presentation on the HSCED method, following which the students read the rich case record and were split into two groups; one group formed the affirmative case, and the second group formed the sceptic case. Each group was facilitated by one of the co-facilitators who assisted the group members in developing their arguments.

Judges

The three independent judges were selected on the basis that they were therapists from another modality, and had experience of participating in a HSCED investigation. The judges were Jane Balmforth, a person-centred counsellor working in a Higher Education college who is currently doing a $\mathrm{PhD}$ in Counselling at the University of Strathclyde studying significant client disclosures in therapy, and who was also a judge in the case for Denise (Widdowson 2012b); Katrin Heinrich, a person-centred/emotion-focused counsellor from Germany with a background in economics and Human Resources who is currently conducting a HSCED study for her MSc in counseling with the University of Strathclyde; and Dr Julie FolkesSkinner, a psychodynamic counsellor and therapist who is a lecturer in psychodynamic counseling at the University of Leicester.

\section{Measures}

In line with procedures and guidelines for the development of a systematic case study (Iwakabe \& Gazzola, 2009; McLeod, 2010), multiple tools were used to build up a complex and detailed collection of quantitative and qualitative data and to assist in the compilation of the rich case record.

(The section below has been reproduced from Widdowson, 2012 as all measures and the procedure for administration of these was identical to the previously reported case of 'Peter')

Quantitative Outcome Measures

Two standardised self-report outcome measures were selected to measure target symptoms (Beck Depression
Inventory- BDI-II) (Beck et al 1996) and global distress/ functional impairment (CORE-OM) (Barkham et al, 2006). These were administered before the first session, and at sessions 8 (mid-way through therapy) and 16 (end of therapy). These measures were also administered at the one-month, three-month and sixmonth follow up periods. These measures were evaluated according to clinical significance (client moved into a non-clinical range score) and Reliable Change Index (Jacobson \& Truax, 1991) (non-clinically significant change). See Table 1 for Reliable Change Index $(\mathrm{RCl})$ values for each measure.

\section{Weekly Outcome Measures}

In order to measure on-going progress, and to facilitate the identification of key therapeutic events which produce significant change, two weekly outcome measures were administered prior to the start of each session. These were CORE-10 (Connell \& Barkham 2007), a ten item shortened version of the CORE-OM which has good correlation with CORE-OM scores and can be used to monitor change. The second measure was the simplified Personal Questionnaire (PQ) (Elliott, et al, 1999). This is a client-generated measure in which clients specify the problems they are wanting to address in their therapy, and rate their problems according to how distressing they are finding each problem. The $P Q$ was also administered at each of the three follow-up intervals.

\section{Qualitative Outcome Measurement}

Qualitative outcome data was collected one month after the conclusion of the therapy. The client was interviewed using the Change Interview protocol (Elliott, 2001) - a semi-structured qualitative change measure which invites the client to explain how they feel they have changed since starting therapy, how they think these changes came about, what they felt was helpful or hindering in the therapy, and what changes they feel they still need to make. As part of this, the client identifies key changes they have made and indicates using a five-point scale whether they expected these changes, how likely these changes would have been without therapy, and how important they feel these changes to be.

\section{Qualitative Data about Helpful Aspects of Therapy}

In order to gain data regarding specific events or aspects of the therapy the client found useful, the client completed the Helpful Aspects of Therapy (HAT) (Llewelyn, 1988) at the end of each session. The HAT asks the client to describe both the most and least helpful aspects of the therapy session and to rate the helpfulness/ unhelpfulness of the session.

\section{Therapist Notes}

The therapist also completed a structured session notes form at the end of each session. The therapist provided a brief description of the session and key issues, 
therapy process, the theories and interventions they used and indicated how helpful they felt the session was for the client.

\section{Adherence}

The therapist also completed a twelve-item adherence form at the end of each session, rating the session on a sixpoint scale. The therapist's supervisor also rated the therapist's work using the same form to verify therapist competence and adherence in providing identifiably TA therapy. (Widdowson, 2012: 5-6)

\section{HSCED Analysis Procedure}

(Note: this section has also been reproduced from Widdowson, 2012 as the guidelines for the development of both the affirmative and sceptic cases are identical to those for the previous case)

\section{Affirmative Case}

The affirmative case is built by identifying positive and convincing evidence to support a claim that the client changed and that these changes primarily came about as a result of therapy. In line with HSCED procedure, to make a convincing case that the client changed positively and as a result of therapy, the affirmative case must be built by identifying evidence for at least two of the following:

1. changes in stable problems: client experiences changes in long-standing problems

2. retrospective attribution: client attributes therapy as being the primary cause of their changes

3. outcome to process mapping: 'Content of the post-therapy qualitative or quantitative changes plausibly matches specific events, aspects, or processes within therapy' (Elliott et. al, 2009; 548)

4. event-shift sequences: links between 'client reliable gains' in the PQ scores and 'significant within therapy' events

\section{Sceptic Case}

The sceptic case is the development of a good-faith argument to cast doubt on the affirmative case that the client changed and that these changes are attributable to therapy. It does this by identifying flaws in the argument and presenting alternative explanations that could account for all or most of the change reported. Evidence is collected to support eight possible non-therapy explanations. These are:

irrelevant

1. Apparent changes are negative or

2. Apparent changes are due to measurement or other statistical error

3. Apparent changes are due to relational factors (the client feeling appreciative of, or expressing their liking of the therapist or an attempt to please the therapist or researcher) (note, this is a term used in the
HSCED approach and does not refer to the impact of the therapeutic relationship as a vehicle for change and relates to factors not directly within the therapy process. The reader is invited to notice the different ways that 'relational' is used within this report, which include this criteria, the therapeutic relationship and a relational approach to therapy)

4. Apparent changes are due to the client conforming to cultural or personal expectancies of change in therapy

5. Improvement is due to resolution of a temporary state of distress or natural recovery

6. Improvement is due to extra-therapy factors (such as change in job or personal relationships etc)

7. Improvement is due to biological factors (such as medication or herbal remedies)

8. Improvement is due to effects of being in the research

Once the sceptic case had been presented, the affirmative team developed rebuttals to the sceptic case. The sceptic team then developed further rebuttals to the affirmative rebuttals, thus providing a detailed and balanced argument.

\section{Adjudication Procedure}

The rich case record and the affirmative and sceptic cases and rebuttals were then sent to the independent judges for adjudication. The judges were asked to examine the evidence and provide their verdict as to whether the case was a clearly good outcome case, a mixed outcome case, or a poor outcome case; to what extent the client had changed and to what extent these changes had been a result of therapy; and to indicate which aspects of the affirmative and sceptic arguments had informed their position. The judges were also asked to comment on what factors in the therapy did they consider to have been helpful and which characteristics about the client contributed to the changes. (Widdowson, 2012: 6)

\section{Results}

\section{Quantitative Outcome Data}

Tom's quantitative outcome data is presented in Table 1. His initial score was within clinical range and above caseness cut-off, thus meeting inclusion criteria for the study. His pre-therapy BDI-II was 24, indicating moderate depression and his CORE-OM score was 18 , indicating mild levels of global distress and functional impairment. All of Tom's quantitative outcome measures demonstrated clinically significant change by session 8, which was maintained throughout therapy and at the one and three-month follow-up periods. Clinically significant improvement on the BDI-II was also maintained at the six-month follow up, and the $P Q$ and CORE data showed reliable change at the six-month follow-up. 
Qualitative Process Data

Tom completed HAT forms at the end of each session and these provided detailed information regarding specific within-session episodes, many of which were related to work with his Child ego-state, two-chair work and Parent ego-state work to identify and resolve aspects of his self-critical process (see examples below from sessions 4, 7 and 8). Other key within-session episodes were connected to exploring his communication patterns and life script and improving his communication and interpersonal style. Tom identified at least one helpful event or theme from each session. The lowest rating for any one event was 7 'moderately helpful'. Eleven therapy events were rated at 8 - 'greatly helpful' and one event was rated at 9 'extremely helpful'. Examples of responses from Tom's HAT forms include;

Session 4: 'Talked at length about the negative voices in my head. Talked to my negative voice in the session. I and my negative voice came to a compromise to work together to protect my child. Realising my negative voice has been serving a purpose. It has been protecting me as a child, but I learned to make it protect me in a more positive way.' (rated 8.5 - 'greatlyextremely helpful')

Session 6: 'We chatted about rackets and the racket feelings I've built up over the years. A racket system was drawn up to show my beliefs, feelings, behaviours and memories while feeling down. Finding ways to give back my racket feelings to my parents' (rated 8 - 'greatly helpful')

Session 7: 'I played the part of myself and my mother. I talked about my mother's childhoood, adult life and her role in parenting. I got a clearer insight into the troubles and inadequacies she had as a child and realized she passed them onto me.' (rated 8.5 - 'greatly-extremely helpful')

Session 8: 'I gave my mother the 'hot potato' back that she'd given to me as a child. After looking back to a very bad childhood experience, I was able to go back and defend my child against my mother. I found the event very satisfying' (rated 9 - 'extremely helpful')

Session 12: 'Talking about ways to communicate better. Really enjoyable. Felt like I was learning as well as in therapy. Learning the different ways of communicating with people' (rated 8.5 - 'greatly- extremely helpful')

\section{Qualitative Outcome Data}

Tom participated in a 90 minute Change Interview at the follow-up interview, one month after concluding his therapy. In the interview, he identified eight changes since starting therapy. The changes are listed below in Table 2 . These changes primarily related to changes in his self-esteem, his way of interpreting others and events and changes in how he communicates and interacts with others

\section{Affirmative Case}

The affirmative team put forward four main lines of evidence which they argued provided clear and compelling evidence that Tom had changed substantially and that these changes had been due to therapy.

The first line of evidence related to significant changes indicated in quantitative and qualitative outcome measures. In compiling the $P Q$ at the pre-therapy intake, Tom identified five main problems which he was seeking to resolve in psychotherapy, all of which were problems of over ten years in duration. All five problems had changed at the level of clinical significance by session 8 , and these changes continued through therapy, and two problems continued to improve slightly after conclusion of therapy by threemonth follow-up. Despite some deterioration between three and six-month follow-up, Tom had continued to maintain reliable change from pre-therapy levels, supporting the argument that his changes had been significant and lasting. The affirmative team considered this to be convincing evidence that Tom changed substantially during the course of therapy, and that these were permanent changes.

The affirmative team also highlighted the detailed description of change that Tom provided in his Change Interview, which included changes in his self-esteem, confidence, problem-solving ability, style of relating to others and how he interpreted events. Additionally, the affirmative team noted that Tom provided additional description of physical changes, such as changes in how he walks and interacts with others which had been pointed out to him by his girlfriend. There was also evidence of significant life changes- Tom had moved to a different city to live with his girlfriend and had left the job he had held since leaving school, starting a new, more challenging job and starting a part-time college course.

The second line of evidence came from Tom's retrospective attribution that his changes had come about as a result of therapy. Although Tom had started his change and self-development process prior to starting therapy, he was clear that therapy had been the main agent of change and described eight changes since starting therapy, and stated that all eight would have been unlikely to have occurred without therapy.

Tom's responses in the Helpful Aspects of Therapy forms provided a third line of evidence by suggesting strong plausible links between therapy interventions and events (for which Tom provided detailed and specific description) and Tom's overall changes. These related to changes in his self-esteem, self-critical process, 
Table 1: Tom's Quantitative Outcome Data

\begin{tabular}{lccc} 
& Beck Depression Inventory-II & CORE-OM & $\begin{array}{c}\text { Personal Questionnaire } \\
\text { (mean score) }\end{array}$ \\
\hline Clinical cut-off & 10 & 10 & 3.00 \\
\hline Caseness cut-off & 16 & 15 & 3.50 \\
\hline Reliable Change Index & 5.78 & 4.8 & 0.53 \\
\hline Pre-Therapy & $\mathbf{2 4}$ & $\mathbf{1 8}$ & $\mathbf{5 . 2}$ \\
\hline Session 8 & $7(++)$ & $6(++)$ & 2.8 \\
\hline Session 16 & $2(++)$ & $2(++)$ & 2.0 \\
\hline 1 month Follow-up & $0(++)$ & $1.7(++)$ & 2.0 \\
\hline 3 month Follow-up & $0(++)$ & $2(++)$ & 1.6 \\
\hline 6 month Follow-up & $6(++)$ & $13.5(++)$ & $\mathbf{4}$ \\
\hline
\end{tabular}

Note: Values in bold italic are within clinical range. + indicates Reliable Change, ++ indicates change to below 'caseness' level.

Figure 1: Weekly and Follow-Up CORE-10 scores (clinical significance 10)

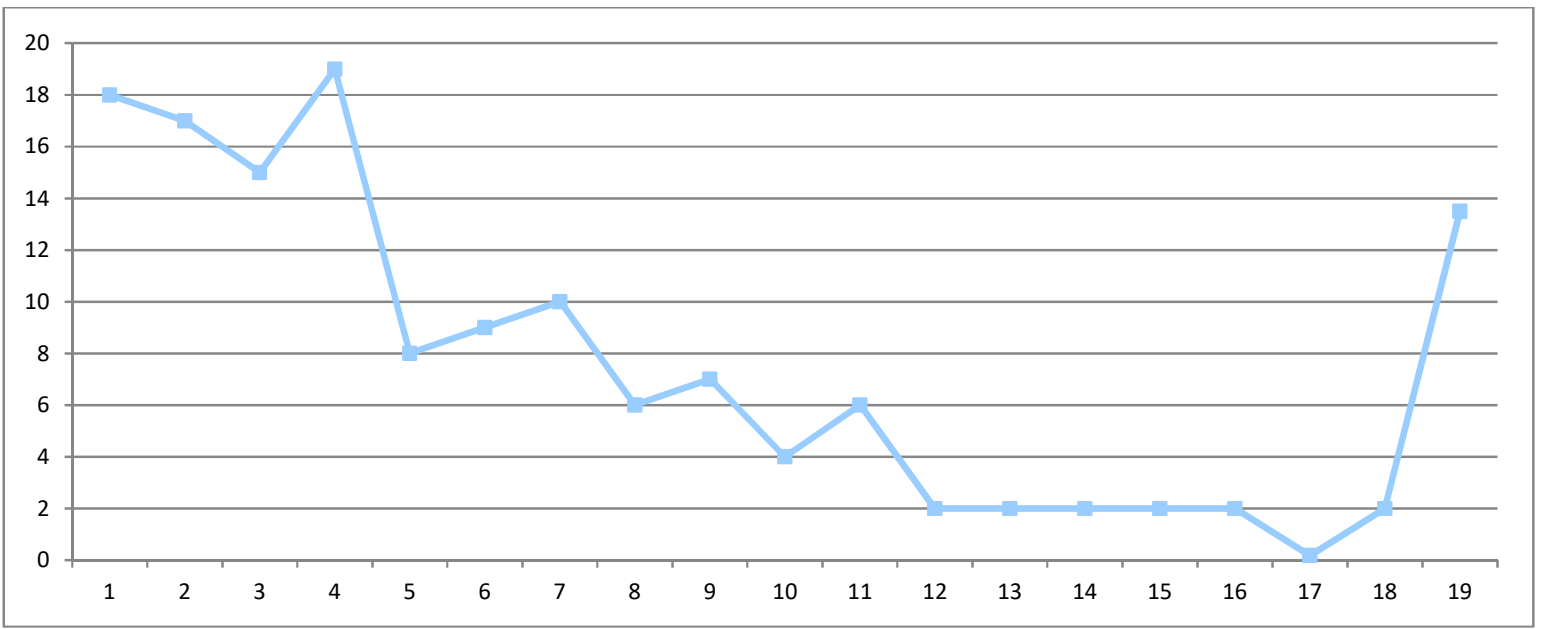

Figure 2: Weekly and Follow-Up mean PQ scores (clinical significance 3)

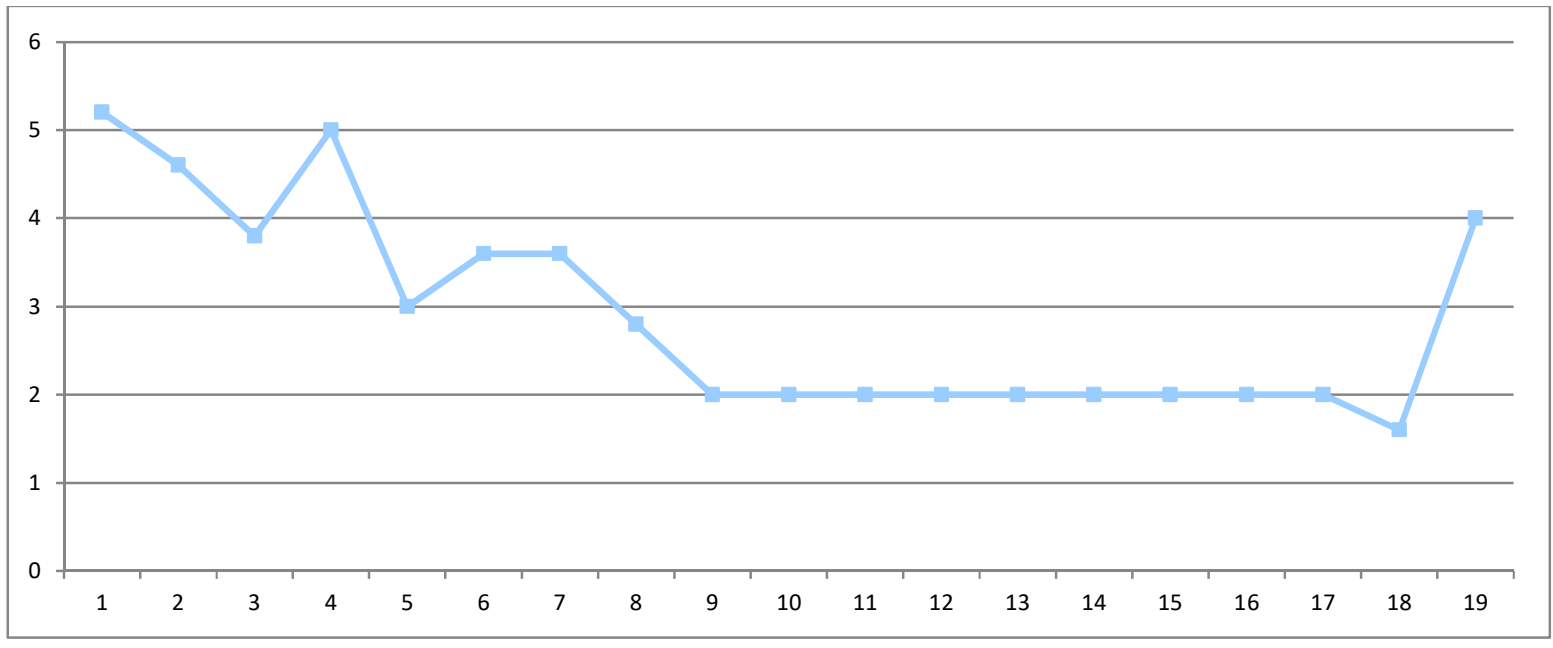


Table 2: Tom's changes as identified in post-therapy Change Interview

\begin{tabular}{|c|c|c|c|}
\hline 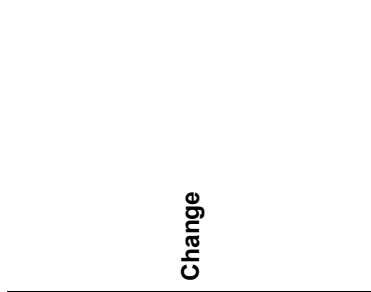 & 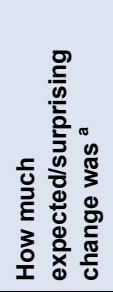 & 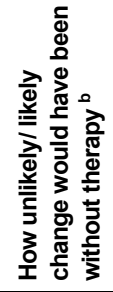 & 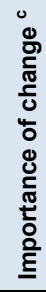 \\
\hline I now think I'm OK as a person & 1 & 1 & 5 \\
\hline $\begin{array}{l}\text { I feel positive and hopeful about } \\
\text { my future }\end{array}$ & 2 & 1 & 5 \\
\hline $\begin{array}{l}\text { I have belief in myself and in my } \\
\text { capabilities - I realise I can do } \\
\text { anything if I really want to }\end{array}$ & 2 & 1 & 5 \\
\hline $\begin{array}{l}\text { I have stopped blaming myself } \\
\text { for everything that goes wrong }\end{array}$ & 3 & 1 & 5 \\
\hline $\begin{array}{l}\text { I have developed problem } \\
\text { solving skills }\end{array}$ & 3 & 1 & 5 \\
\hline $\begin{array}{l}\text { I have found ways to understand } \\
\text { other people and communicate } \\
\text { better }\end{array}$ & 5 & 1 & 5 \\
\hline $\begin{array}{l}\text { I have learned to take a step } \\
\text { back in situations and not take } \\
\text { things personally }\end{array}$ & 4 & 1 & 5 \\
\hline $\begin{array}{l}\text { I am more sociable and don't } \\
\text { withdraw in social situations }\end{array}$ & 2 & 1 & 5 \\
\hline
\end{tabular}

a The rating is on a scale from 1 to 5 ;

$1=$ expected, $3=$ neither, $5=$ surprising

$\mathrm{b}$ The rating is on a scale from 1 to 5 ;

$1=$ unlikely, $3=$ =neither, $5=$ likely

c The rating is on a scale from 1 to 5 ;

1=slightly, 3 = moderately, 4=very, 5=extremely

increased insight into the origins of his problems, exploration of his relationships with others, interpersonal changes and the development of a sense of hope for the future.

The fourth line of evidence related to clear and convincing event-shift sequences where significant sessions (which Tom had rated as helpful and also described in his post-therapy Change Interview) corresponded with a subsequent reliable change on his weekly $\mathrm{PQ}$ and CORE scores. Although Tom demonstrated consistent gradual improvement from the outset, sessions 4,7 and 8 in particular all seemed to result in substantial improvement and were sessions which both Tom and his therapist highlighted as important. In the Change Interview Tom provided a description of the specific therapy events which took place in the sessions which he felt had produced these therapeutic shifts.

\section{Sceptic Case}

The sceptic team considered that although it was clear that Tom did indeed change, there was evidence to cast doubt on claims that these changes came about as a direct result of therapy. In particular, the sceptic team highlighted that there appeared to be strong evidence of expectancy factors in Tom's case and that it was also possible that his self-help efforts had a greater effect than the therapy and were a primary cause of his changes. Furthermore, the sceptic team considered that it was possible that some of Tom's changes could be associated with a strong positive transference to his therapist (relational factors) as opposed to internal restructuring. Finally, the sceptic team noted that although Tom had shown reliable improvement from pre-therapy levels, his scores on all outcome measures at six-month follow up had shown reliable deterioration from the three-month follow-up therefore suggesting that his changes were temporary and not associated with deep, permanent internal changes.

\section{Affirmative Rebuttal}

The rebuttal of the affirmative team rejected the possibility of relational factors as a significant factor which they considered was not supported by a detailed examination of the evidence. The affirmative team emphasized that, although Tom was very positive about his therapy and his therapist, his account was well balanced with a clear description of many aspects of the therapy which he found to be difficult and painful. Also, the affirmative team considered that Tom's description of the therapy process was plausible and realistic and his description of the therapy was not overly focused on the therapist, but more on the process of therapy indeed Tom provided very little in the way of positive description of his therapist, preferring to describe specific within-therapy events.

The affirmative team highlighted that Tom's changes were maintained at the three-month follow-up and although they showed deterioration at the six-month follow up, argued that this was a temporary state of distress and could be entirely accounted for by the external changes in his life - he had moved to a different city, has started living with his partner and her children, had a new challenging job and had started a college course - all of which are major life changes and would be likely to require considerable adjustment. In support of this argument, they cited Tom's statement at sixmonth follow-up that he was "happy, contented and not 
really worried about the future" and that he no longer feels like a failure, arguing that it would be unlikely that he would make these statements if his self-esteem had significantly deteriorated.

The affirmative team's rebuttal rejected the argument that Tom's changes could be accounted for by expectancy or due to the effects of self-help efforts by citing that although Tom had engaged in pre-therapy reading, in his Change Interview he stated clearly that his reading had only taken him so far and that he was aware of the limitations of self-help strategies for facilitating change. The affirmative team also considered it only natural that a client would come to therapy with clear expectations of change in specific problem areas and would anticipate improvement in those areas, particularly if they had engaged in reading which explained the nature of the changes people can gain from therapy. They also noted that although Tom did have some positive expectations of change, he did indeed find some of his changes to be very surprising in particular those relating to interpersonal changes.

The affirmative team once again emphasized their view that Tom changed substantially and that the evidence that these changes were a result of therapy was so compelling and supported by triangulation of all quantitative and qualitative measures which converged to form repeatedly supported and substantiated evidence supporting these claims, and that the arguments put forward by the sceptic team were not sufficient to account for changes of the magnitude of Tom's.

\section{Sceptic Rebuttal}

The sceptic rebuttal remained focused on the strong possibility of relational factors, expectancy and self-help strategies in promoting change. The sceptic rebuttal also considered the possibility that the specific withintherapy events Tom described may have been highly emotional experiences for him, but not ones which produced lasting change.

Additionally the sceptic rebuttal emphasised the reliable deterioration in all of Tom's outcome measures, to a level which moved him back into clinical levels of distress on his $P Q$ and CORE scores, as indicating that his changes were not permanent and that his optimism in his six-month follow-up statement may have been associated with 'wishful thinking' as opposed to deep internal changes. In particular, the sceptic team noted that at the six-month follow-up Tom had started to experience a return in his self-criticism and feeling socially inferior to others, again suggesting his changes were temporary.

\section{Adjudication}

The three judges separately reviewed the rich case record and affirmative and sceptic cases and independently produced their reports regarding their verdicts on the case. Their reports included reference to the particular evidence they had drawn on in forming their opinions and described the moderator and mediator factors which they considered were significant in the case. The judges' verdicts and a mean score of all three judges' conclusions are presented below in Table 3.

The majority verdict of the judges was that this was a positive outcome case, with Tom experiencing clinically significant change and had changed considerablysubstantially and that these changes were considerablysubstantially due to therapy.

Summary of opinions regarding how the judges would categorise this case

(Clearly good outcome - problem completely solved, Mixed outcome - problem not completely solved, Negative/ Poor Outcome)

There was a majority conclusion that this was a good outcome case, with two of the judges considering this a clearly good outcome case and the third judge considering this a mixed outcome case (problem not completely solved). This gave a mean score for clearly positive outcome at $70 \%$ and a mean score for mixed outcome at $80 \%$. The judges cited that both the qualitative data from the Change Interview and the quantitative outcome data demonstrated positive change with a general trend towards recovery. Judge $C$ explained her scepticism about the outcome as relating to the decline at the six-month follow up, and although she felt that Tom had clearly benefitted from therapy, he had experienced some deterioration and was struggling to manage some of his current stressors and this suggested that Tom was not able to respond to these in a fully resourceful way which maintained his gains.

Summary of opinions regarding the extent to which the client had changed

The verdict of judges $A$ and $B$ was that Tom had changed substantially whilst judge C's verdict was that he had changed considerably, giving a mean score of Tom's changes during therapy of $73.3 \%$. The judges all agreed on their level of confidence in their conclusions, with a certainty level of $80 \%$.

Summary of opinions as to whether the changes were due to the therapy

Judges $A$ and $B$ were in agreement that Tom's changes were substantially $(80 \%)$ due to the effects of therapy, whereas judge $\mathrm{C}$ felt that his changes were considerably due to therapy $(60 \%)$, which resulted in a mean verdict that Tom had changed considerablysubstantially due to therapy $(73.3 \%)$.

Judge $\mathrm{C}$ noted that the major life changes which Tom had made by the six-month follow-up provided 


\begin{tabular}{|c|c|c|c|c|}
\hline & Judge A & Judge B & Judge C & Mean \\
\hline \multicolumn{5}{|l|}{ 1. How would you categorise this case? How certain are you? } \\
\hline 1a. Clearly good outcome (problem completely solved) & $100 \%$ & $70 \%$ & $40 \%$ & $70 \%$ \\
\hline 1b. Mixed Outcome (problem not completely solved) & $\begin{array}{l}\text { (score not } \\
\text { given) }\end{array}$ & $100 \%$ & $60 \%$ & $80 \%$ \\
\hline 1c. Negative/Poor Outcome & $0 \%$ & $0 \%$ & $20 \%$ & $6.6 \%$ \\
\hline 2. To what extent did the client change over the course of therapy? & $\begin{array}{c}80 \% \\
\text { Substantially }\end{array}$ & $\begin{array}{c}80 \% \\
\text { Substantially }\end{array}$ & $\begin{array}{c}60 \% \\
\text { Considerably }\end{array}$ & $\begin{array}{c}73.3 \% \\
\text { Considerably- } \\
\text { Substantially }\end{array}$ \\
\hline 2a. How certain are you? & $100 \%$ & $80 \%$ & $60 \%$ & $80 \%$ \\
\hline 3. To what extent is this change due to therapy? & $\begin{array}{c}80 \% \\
\text { Substantially }\end{array}$ & $\begin{array}{c}80 \% \\
\text { Substantially }\end{array}$ & $\begin{array}{c}60 \% \\
\text { Considerably }\end{array}$ & $\begin{array}{c}73.3 \% \\
\text { Considerably- } \\
\text { Substantially }\end{array}$ \\
\hline 3a. How certain are you? & $100 \%$ & $80 \%$ & $60 \%$ & $80 \%$ \\
\hline
\end{tabular}

persuasive evidence that Tom had changed to the extent that he was able to make radical changes in his life and build a satisfying relationship with his 'new family'. The judges were all in agreement that although his pre-therapy reading had been useful to him, this had not resulted in major life change and that it was unlikely that expectancy factors would produce these life changes. It was also noted by the judges that in spite of the deterioration at six-months, Tom was able to maintain a positive outlook about his future.

\section{Mediator factors}

The judges were asked to provide their opinion on which therapist characteristics, therapeutic factors and processes had been most helpful in this case.

Judges $A$ and $B$ agreed that the therapist's use of twochair methods had been pivotal in this case, and had helped Tom to deal with his self-critical process (largely associated with his harsh Parental introjects), express emotions, see things from a different perspective and in particular resolve aspects of his emotions and script decisions connected to his historical relationship with his mother.

Judge A noted that the 'life map' exercise at the outset of therapy had clearly been an important, emotional and helpful experience for Tom. Judge $B$ also noted that aspects of the therapy which provided Tom with practical strategies for improving his communication style with others were also important and felt that the use of TA concepts to help Tom conceptualise his process (such as rackets, script, permissions and ego states) had also been helpful. Judge B highlighted the empathic, non-judgmental and highly active approach of the therapist had been important in this case and noted that the therapist successfully processed and repaired an alliance rupture at session 6 which had been helpful.

\section{Moderator factors}

The judges were asked to comment on client factors, including the client's resources and approach to the therapy which had enabled them to make the most of the therapy and enhanced the therapy process. All judges agreed that Tom's pre-therapy reading and research into TA, hope for change and his clear motivation and readiness to change had been helpful factors that had enabled him to engage with the therapist and the therapy process. The judges also agreed that Tom's determination and willingness to engage with painful emotions and life experiences, and to actively make use of the therapy to resolve painful emotions associated with his past, his problems and underlying issues had been a factor. Judge $C$ noted that Tom's desire to have a more satisfying relationship with his partner and her children and the fact that Tom was paying privately for therapy had also likely been motivating factors which had inspired him to engage in the change process.

\section{Discussion}

The majority conclusion of the judges was that this was a clearly good outcome case, with the caveat that there was evidence to suggest Tom was experiencing some difficulties associated with his life changes at the sixmonth follow-up. There were several interesting 
technical features in this present case which are highly relevant to TA therapists and which suggest further avenues for future research.

The positive use of self-reparenting as a therapeutic intervention in Tom's case adds support to the study conducted by Wissink (1994) who found that participants in a six week TA-based self-reparenting group experienced a significant increase in self-esteem. A control group had no increase in self-esteem during the same time period, suggesting that the selfreparenting method was effective at increasing selfesteem, feelings of self-efficacy and self-actualisation. This would suggest that as a method, self-reparenting holds promise and that further research which investigates the outcome of self-reparenting is warranted.

Tom made extensive use of two-chair techniques at several points during his therapy and this was highlighted by the judges as a significant intervention which yielded several critical change points. This supports the findings of Shahar et al (2011) who recently conducted a study which concluded that the use of two-chair work with clients who were self-critical was associated with significant increase in selfcompassion and significant decreases in self-criticism, depressive symptoms and anxiety. This study is of particular relevance to TA therapists, as it was investigating the use of Emotion-Focused Therapy (EFT); an empirically-supported therapy which integrates principles of person-centred and gestalt therapy and which extensively utilises two-chair methods. EFT therapists view self-criticism as a key component of several psychological disorders and conceptualise self-criticism as "a conflict split between two aspects of the self, where one part of the self harshly criticizes, judges, evaluates and blocks the experiences and healthy needs of another, more submissive part of the self" (p. 763). They use a "twochair intervention (where) the client is asked to enact a dialogue between the inner critic and the experiencing self using two chairs. The client is asked to "be" the inner critic and speak to the experiencing self using one chair and then enact the experiencing self and respond to the self-critical attacks from the second chair. During the dialogue, the client switches chairs whenever the roles are switched, using empathic guidance and emotion coaching from the therapist to explore, process and provide space for expressing emotions and needs associated with each part of the self' (p. 763).

Clearly, this method has direct parallels with redecision methods in TA psychotherapy, and in particular the Parent Interview (McNeel, 1979) and Impasse Resolution (Goulding \& Goulding, 1979). This suggests that further research which investigates the outcomes of the use of TA and in particular redecision methods for therapy of self-criticism may prove fruitful in the treatment of a wide range of disorders.

Most significantly for the TA community, this third positive outcome case which demonstrated clinically significant change means that TA psychotherapy now has modest research evidence for the treatment of depression and that we are able to state that TA has met initial criteria to be considered as an evidencebased therapy for the treatment of depression, meeting criteria as possibly efficacious for the treatment of depression (Chambless \& Hollon, 1998). Clearly further positive replication will strengthen these claims, and a further six positive outcome cases will enable TA therapy to meet criteria for being demonstrably efficacious for the treatment of depression.

A cross-case comparison with the previous cases in this series is starting to highlight a number of significant trends which appear to have had a positive impact on the success of these cases. Firstly, the impact of client motivation and readiness for change (Zuroff, et al 2007) and client preferences in terms of choice of therapy and therapist (Swift, et al 2011) was important in this case, as well as the cases of Peter (Widdowson, 2012a) and Denise (Widdowson, 2012b) suggesting that these factors may be significant in contributing to positive outcomes of therapy. Therapeutic relationship factors were once again significant, with the active therapist approach and an atmosphere of permissiveness and the genuine caring of the therapist all being important factors in the outcome.

\section{Limitations}

There was some variability in how the judges presented their verdicts. The judges were not given any specific instructions in how to complete the forms and it is possible that detailed instruction for judges in giving their verdict may have resulted in more agreement or consistency in how they presented their conclusions as percentages.

The sceptic team conceded that they struggled to form their argument as they were of the general opinion that this was a good outcome case. This may have resulted in their argument being less well-formed than that of the affirmative team. Similarly, the analysis team and judges were all psychotherapists, and so already convinced of the effectiveness of therapy, and it is possible that introducing lay people into the analysis and adjudication process may result in different conclusions being drawn.

Tom showed some decline at the six-month follow-up period and although it is possible that this was associated with stresses from his life changes, a longer follow-up period in future cases may provide more information on long-term benefit from therapy. 
Judge $C$ speculated that more detailed analysis of Tom's CORE sub-scales, particularly those relating to problems and functioning, may have revealed a more nuanced and accurate picture of his situation at the sixmonth follow up, perhaps indicating that his functioning had improved in spite of a deterioration in his problems. This is an interesting point, and one which is worthy of further investigation.

Furthermore, this was not a 'pure' case of depression and it is possible that Tom's comorbid social anxiety may have provided some ambiguity in the outcomes and makes interpretation of findings, including conclusions regarding the effectiveness of TA as a specific treatment for depression, somewhat problematic. Nevertheless, the case of Tom is one which will no doubt resonate with many TA practitioners as being similar to many cases they encounter in everyday routine practice, and therefore the applicability and generalisability of the findings from this case appear to have high face validity.

\section{Conclusion}

This present study once again found TA psychotherapy to be an effective treatment for depression and supports the previous TA research by Fetsch \& Sprinkle (1982), van Rijn et al (2011) and Widdowson (2012a; 2012b) and significantly adds to the TA evidence base by providing a third positive outcome systematic case study, thus enabling TA to be considered for recognition as possibly efficacious for the treatment of depression (Chambless \& Hollon, 1998).

This present study complements the previous two cases in supporting the view that client motivation, readiness to change and the client actively seeking out and engaging with a TA therapist are likely to be significant factors influencing the outcome. Again, a good therapeutic relationship with an active and empathic therapist appeared to have been significant. This present case also suggests that further research into specific TA therapeutic processes, in particular selfreparenting and two-chair work, is warranted.

Mark Widdowson, Teaching and Supervising Transactional Analyst (Psychotherapy), Associate Director, The Berne Institute, Ph D student, University of Leicester, can be contacted on: mark.widdowson1@btopenworld.com

The author wishes to thank the members of the analysis team: Jane Bernard, Isabel Burns, Phil Crawley, Mike Day, David Harford, Colin Kerr and Owen Vaughan. Particular thanks also are due to Katie Banks for her invaluable contribution in co-facilitating the analysis groups.

The author also acknowledges with grateful thanks the support of Physis Training in Edinburgh, which provided the venue and participants for the workshop at which the affirmative and sceptic cases were developed.

\section{References}

American Psychiatric Association (Ed.) (1994) Diagnostic and Statistical Manual of Mental Disorders- fourth edition. Washington, DC: American Psychiatric Association

Bagby, R.M., Cox, B. J., Schuller, D.R., Levitt, A.J., Swinson, R.P. \& Joffe, R.T., (1992) 'Diagnostic specificity of the dependent and self-critical personality dimensions in major depression', Journal of Affective Disorders, 26: 59-64

Barkham, M., Mellor-Clark, J., Connell, J., \& Cahill, J. (2006). A core approach to practice-based evidence: a brief history of the origins and applications of the CORE-OM and CORE system. Counselling and Psychotherapy Research, 6(1): 3-15.

Beck, A.T., Ward, C.H., Mendelssohn, M.J. \& Erbaugh J. (1961) 'An inventory for measuring depression'. Archives of General Psychiatry, 4: 561-571

Beck, A.T., Steer, R.A., \& Brown, G.K. (1996) Manual for the Beck Depression Inventory-II. San Antonio, TX: Psychological Corporation

Berne, E. (1972) What do you say after you say hello?, New York: Corgi

Blatt, S.J ( 1991) 'A cognitive morphology of psychopathology', Journal of Nervous and Mental Disorders, 179: 449- 458

Chambless, D.L. \& Hollon, S.D. (1998) Defining Empirically Supported Therapies. Journal of Consulting and Clinical Psychology, 66(1): 7-18

Clarkson, P. (1992) Transactional Analysis: An Integrated Approach. Hove: Routledge

Cox, B.J., Rector, N.A., Bagby, R.M., Swinson, R.P., Levitt, A.J. \& Joffe, R.T. (2000) 'Is self-criticism unique for depression? A comparison with social phobia', Journal of Affective Disorders, 57 : 223-228

Cox, B.J., Walker, J.R., Enns, M.W. \& Karpinski, D.C. (2002) 'Selfcriticism in generalized social phobia and response to cognitive behavioral treatment'. Behavioural Therapy, 33: 479-491

Cox, B.J., Fleet, C. \& Stein, M.B. (2004) 'Self-criticism and social phobia in the US national comorbidity survey', Journal of Affective Disorders, 82: 227-234

Dattilio, F.M., Edwards, D.J.A., \& Fishman, D.B. (2010) 'Case studies within a mixed methods paradigm: Toward a resolution of the alienation between researcher and practitioner in psychotherapy research.' Psychotherapy Theory, Research, Practice, Training, 47(4): 427-441

Elliott, R. (2001). Hermeneutic single case efficacy design (HSCED): An overview. In K.J. Schneider, J.F.T. Bugental \& J.F. Fraser (eds.), Handbook of Humanistic Psychology (pp315-324), Thousand Oaks, CA: Sage.

Elliott, R. (2002) Hermeneutic Single-Case Efficacy Design. Psychotherapy Research, 12(1): 1-21

Fetsch, R. J., \& Sprinkle, R. L. (1982) 'Stroking treatment effects on depressed males', Transactional Analysis Journal, 12(3): 213-7

Iwakabe, S. \& Gazzola, N. (2009) From single-case studies to practice-based knowledge: aggregating and synthesizing case studies. Psychotherapy Research, 19, 601-611 
Jacobson, N. S., \& Truax, P. (1991). Clinical significance: A statistical approach to defining meaningful change in psychotherapy research. Journal of Consulting and Clinical Psychology, 59: 12-19

Llewelyn, S. (1988) Psychological therapy as viewed by clients and therapists. British Journal of Clinical Psychology, 27, 223-238.

McLeod, J. (2010). Case Study Research in Counselling and Psychotherapy. London: Sage

McLeod, J. \& Eliott, R. (2011) 'Systematic case study research: A practice-oriented introduction to building an evidence base for counselling and psychotherapy', Counselling and Psychotherapy Research, 11(1): 1-10

Sachs-Ericsson, N., Verona, E., Joiner, T. \& Preacher, K.J. (2006) 'Parental verbal abuse and the mediating role of self-criticism in adult internalizing disorders', Journal of Affective Disorders, 93: 71 78

Shahar, B., Carlin, E.R., Engle, D.E., Hegde, J., Szepsenwol, O. \& Arkowitz, H. (in press) 'A pilot investigation of emotion-focused twochair dialogue intervention for self $\square$ criticism', Clinical Psychology and Psychotherapy, DOI: 10.1002/cpp.762

Stephen, S \& Elliott, R. (2011) 'The Adjudicated Case Study Method' Pragmatic Case Studies in Psychotherapy, 7(1): 230-241 (article available at: http://pcsp.libraries.rutgers.edu) Downloaded 4th March 2011

Stephen, S., Elliott, R. \& MacLeod, R. (2011) 'Person-centred therapy with a client experiencing social anxiety difficulties: A hermeneutic single case efficacy design', Counselling and Psychotherapy Research, 11(1): 55-66

Stewart, I. \& Joines, V. (1987) TA Today: A New Introduction to Transactional Analysis. Nottingham: Lifespace
Swift, J.K., Callahan, J.L. \& Vollmer, B.M. (2011) 'Preferences', Journal of Clinical Psychology: In Session. 67(2): 155-165

van Rijn, B., Wild, C., \& Moran, P. (2011) 'Evaluating the Outcomes of Transactional Analysis and Integrative Counselling Psychology within UK Primary Care Settings', International Journal of Transactional Analysis Research. 2(2): 34-43

Widdowson, M. (2010) Transactional Analysis: 100 Key Points and Techniques. Hove: Routledge

Widdowson, M. (2011) 'Case Study Research Methodology', International Journal of Transactional Analysis Research. 2(1): 25 34

Widdowson, M. (2012a) 'TA Treatment of Depression - A Hermeneutic Single-Case Efficacy Design Study - "Peter" ', International Journal of Transactional Analysis Research. 3(1): 3-

Widdowson, M. (2012b) 'TA Treatment of Depression - A Hermeneutic Single-Case Efficacy Design Study- "Denise", International Journal of Transactional Analysis Research 3 (2) 3-14

Wissink, L. M. (1994) 'A validation of transactional analysis in increasing self-esteem among participants in a self-reparenting program'. Transactional Analysis Journal. 24(3): 189-96.

Woollams, S. \& Brown, M. (1979) TA: The Total Handbook of Transactional Analysis. NJ: Prentice-Hall

Zuroff, D.C., Koestner, R., Moskowitz, D.S., McBride, C. Marshall, M. \& Bagby, R.M. 'Autonomous motivation for therapy: A new common factor in brief treatments for depression', Psychotherapy Research. 17(2): 137-147 